\title{
DISTRITAL MISTO (SPP): UMA REVISÃO SOBRE A PROPOSTA DE REFORMA ELEITORAL DO TSE
}

\author{
Bruno Veçozzi Regasson ${ }^{1}$
}

\begin{abstract}
Resumo
Este trabalho busca realizar uma revisão de literatura sobre o debate de reforma eleitoral acendido pelo Tribunal Superior Eleitoral no ano de 2019 através da proposta de adoção do sistema eleitoral proporcional personalizado (o "distrital misto"). Para isso, mobiliza trabalhos que discutem pontos centrais para a discussão: os impactos do sistema eleitoral proporcional no Brasil, o que a literatura dedutiva prescreve sobre o sistema proporcional personalizado e o debate sobre as consequências do SPP no país que serve de modelo para o relatório do TSE, a Alemanha. Aponta-se assim que o projeto de alteração legislativa ancora-se nos diagnósticos mais pessimistas do sistema proporcional: as acusações de baixa representatividade, baixa accountability, excessiva competição intra-partidária, fragmentação e enfraquecimento do sistema partidário, personalização da política. A literatura sobre o SPP aponta para um sistema com vínculos eleitor-eleito mais diretos e geográficos, com alto índice de estabilidade; destaca os perigos da delimitação de distritos eleitorais; defende que listas fechadas diversificam candidaturas e viabilizam candidatos mais sensíveis, diminuem a capacidade de eleitores manifestarem-se adequadamente, desincentivam a personalização de eleições, incentivando a propaganda de programas partidários e empoderam partidos políticos; preocupa-se com a criação de dois conjuntos diferentes de deputados com status e interesses diferente; restringe a competição intrapartidária para o período pré-eleitoral, aumentando a força das elites partidárias e a lealdade dos candidatos aos partidos; postula que as regras majoritárias incentivam fortemente a centralização do sistema partidário; e denuncia que o sistema de duas regras pode resultar em um alto nível de desproporcionalidade votos - cadeiras. Acredita-se que a exploração dessa discussão ajuda a iluminar o debate público, clareia a sua re-inserção na agenda política e a intencionalidade de atores envolvidos no processo decisório.
\end{abstract}

Palavras-Chave: Sistemas eleitorais; Sistema proporcional brasileiro; Sistema proporcional personalizado; Distrital misto.

1 Mestrando de Sociologia e Ciência Política na Universidade Federal de Santa Catarina, brunovregasson@ hotmail.com, orcid.org/0000-0002-2703-023X. 


\section{INTRODUÇÃO}

No dia 10 de junho de 2019 o Tribunal Superior Eleitoral realizou uma reunião com o presidente da Câmara dos Deputados Rodrigo Maia (DEM) com o objetivo de formalizar a entrega do resultado dos estudos de um Grupo de Trabalhos constituído na Corte em fevereiro desse mesmo ano. Instituído pela Presidência do Tribunal (Rosa Weber) e coordenado pelo ministro Luís Roberto Barroso, o GT tem como objetivo "apresentar sugestões acerca da reforma do sistema eleitoral e da legislação eleitoral" ${ }^{\prime 2}$ e segue em funcionamento. O relatório entregue apresenta uma proposta de alteração legislativa para o processo eleitoral: a substituição do nosso sistema eletivo proporcional por um sistema distrital misto.

O sistema de representação proporcional tem sido uma das poucas constantes institucionais brasileiras: desde 1945, elegemos deputados e vereadores utilizando o mesmo sistema. O sistema, no entanto, não existe sem uma grande dose de críticos na arena política e acadêmica. Em 2019, essa antiga polêmica parece voltar à arena pública com força renovada: o TSE chegou a sugerir que a proposta pudesse ser posta à teste em 2020 em eleições municipais de cidades com mais de 200 mil habitantes; Maia já encampou uma defesa pública dessa agenda, tendo divulgado o projeto de criação de uma comissão especial na Câmara para o assunto ${ }^{3}$.

Este artigo busca contribuir para a discussão. Primeiramente se realizará uma breve revisão em torno do sistema proporcional brasileiro: seu funcionamento específico, as mais significativas alterações que esse sofreu desde 1945 até o presente (07/2019) e o estado da arte do empreendimento acadêmico sobre sua operacionalização e consequências na prática política nacional. Depois se realizará um apanhado das disputas argumentativas sobre as implicações do sistema proposto pelo TSE, o distrital misto/sistema proporcional personalizado, partindo da análise da íntegra do relatório assinado pelo GT e discutindo a sincronia dos debates acadêmicos com dois dos três autoproclamados objetivos da proposição de reforma eleitoral: “(i) aumentar a representatividade (a legitimidade democrática) do sistema político" e “(iii) facilitar a governabilidade.”

Acredita-se que uma investigação dessa natureza possa contribuir para esclarecer não apenas o debate, mas sua re-inserção na agenda política e a intencionalidade de atores envolvidos no processo decisório.

\footnotetext{
2 Portaria $\mathrm{n}^{\circ} 114$, de 13 de fevereiro de 2019.

3 Informações veiculadas em O Globo. Na reportagem, a fala do Presidente da Câmara: “[...] o sistema distrital misto num país continental como nosso, para mim certamente é a melhor proposta." Ver: https://oglobo.globo.com/brasil/tse-propoe-mudanca-do-sistema-eleitoral-ja-para-2020-23730221
} 


\section{SISTEMA PROPORCIONAL DE LISTA ABERTA BRASILEIRO: UM BREVE HISTÓRICO (1932 - PRESENTE)}

A primeira versão de representação proporcional de lista aberta para as Câmaras dos Deputados e Assembleias Legislativas adotada no Brasil foi estipulada em 1932. Trata-se de notável longevidade para um sistema eleitoral: nenhum país utiliza tal sistema há tanto tempo no mundo. Em 1933 e 1934 os eleitores podiam escolher votar em tantos candidatos quantas fossem as cadeiras do estado na Câmara dos Deputados mais um. Em 1935, esta regra foi alterada, definindo o voto único. A suspensão das eleições pela ditadura Vargas (1937 - 1945) adiou a primeira bateria de votações a ser exercida sob a nova regra para 1945.

Desde então, o sistema brasileiro mantém-se estável em termos gerais. A regra estabelece duas opções ao eleitor: o voto em nome (candidato) e o voto em partido (legenda). Os partidos definem a lista de candidatos - que é alta em termos comparativos, podendo os partidos apresentarem uma lista de até uma vez e meia o número de cadeiras da circunscrição eleitoral ${ }^{4}$ - e as cadeiras são ocupadas pelos candidatos mais votados de cada lista. O número de cadeiras que cada partido receberá depende da soma total de todos os votos dos candidatos da lista mais os votos na legenda. A quantidade de votos válidos é dividida pela quantidade de vagas do domicílio eleitoral, gerando o chamado quociente eleitoral, número pelo qual os votos válidos do partido são divididos (gerando o chamado quociente partidário). Algumas alterações significativas nesta fórmula geral merecem destaque: desde 1950 a distribuição de cadeiras é realizada pelo método D’Hont; desde 1998, votos brancos e nulos foram retirados das equações. Também em 1998 foram instauradas cotas de gênero para as candidaturas, definindo uma proporção de 30\% - 70\%. Em 2015, foi aprovado o quociente eleitoral de votação individual, um limite mínimo de votação individual de $10 \%$ do quociente eleitoral para preenchimento das vagas nas eleições proporcionais - uma significativa alteração na distribuição de cadeiras que objetivou atacar o fenômeno dos "puxadores de voto". Os partidos políticos podiam, até a eleição de 2018, formar coligações nas eleições proporcionais. Nestes casos, podiam apresentar listas com até duas vezes o número de cadeiras e tinham seus quocientes calculados com a soma do voto de todos os partidos coligados. Em 2017, porém, o Congresso promulgou lei proibindo as coligações proporcionais já em 2020. A mesma emenda constitucional ainda estabeleceu a cláusula de desempenho, que define uma votação mínima (que crescerá exponencialmente até os 3\% dos votos

\footnotetext{
4 Apesar desse incentivo geral para apresentar muitos nomes, nenhum partido conseguiu preencher sozinho todas as vagas disponíveis nas três eleições para a Câmara dos Deputados de 1994, 1998 e 2002, aponta NICOLAU (2006).
} 
válidos em 2030) para a legenda ter acesso ao Fundo Partidário e à propaganda gratuita de rádio e TV. Finalmente, o desenho possui um dispositivo intencionalmente desproporcional: ele superrepresenta os estados menos populosos, que são geralmente os mais pobres (que devem ter no mínimo oito assentos), e sub-representa os mais populosos (que devem ter no máximo setenta), especialmente São Paulo. ${ }^{5}$

Os estudos sobre o sistema eleitoral brasileiro tem crescido nos últimos anos, mas geram polêmicas dentro da academia há muito tempo. É importante ressaltar que os recortes tradicionais do campo influenciaram os estudos locais, com o protagonismo das generalizações realizadas a partir de estudos de caso e dos esforços tipológicos e dedutivos.

Nos anos 90 três foram os estudos de grande impacto sobre o tema na área. Barry Ames (1995) contribui ao debate mesmo interessado centralmente na relação entre deputados eleitos, seus centros eleitorais e seu sucesso eletivo. Sua tese central é de que deputados brasileiros direcionam emendas orçamentárias em benefício das municipalidades onde procuraram votos nas eleições seguintes ao mandato, o que constitui um padrão de comportamento particularista e localista incentivado pelas regras da lista aberta. David Samuels (1999) também o faz de modo indireto: sua preocupação central era explicar o sucesso do Partido dos Trabalhadores em construir reputação partidária em um sistema centrado em candidatos. Esse personalismo, sugeriu Samuels, é consequência das normas descentralizadas de controle de nomeações de candidatos em parte decorrente do sistema eleitoral proporcional. Mas o diagnóstico de Scott Mainwaring (1991) foi o de maiores repercussões na academia. Estudo comparado (o Brasil aparece ao lado de outros sistemas de voto preferencial como a Itália, o Chile e a Finlândia) e fortemente dedutivo (a crítica mais frequente que Mainwaring receberia posteriormente seria a falta de manuseio de dados empíricos), o texto de 1991 produz uma visão bastante pessimista: "a legislação eleitoral reforça o comportamento individualista dos políticos e impede a construção partidária", "os graus extremamente baixos de fidelidade e disciplina partidária encontrados nos principais partidos [...] são tolerados e estimulados por essa legislação", "os políticos brasileiros optaram sempre por um sistema eleitoral que tende a enfraquecer os partidos" e "agiram assim para proteger seus próprios interesses [ajudando] a manter o caráter elitista do sistema político como um todo." (MAINWARING, 1991, p. 35) Além disso, "as normas de funcionamento do Congresso estimulam a formação de novos partidos" (ibidem, p. 42), o que contribui para uma profunda fragmentação no sistema partidário.

\footnotetext{
5 Ressalta-se que esta disparidade entre estados não se pretende alterada pela proposta do Tribunal Superior Eleitoral, o que só pode ser feito via Projeto de Emenda Constitucional enquanto a adoção do distrital misto pode ser realizada via lei ordinária.
} 
Jairo Nicolau (2006) produz a mais vasta revisão do campo empírico e do debate intelectual sobre o objeto. Seu prognóstico sobre os efeitos se concentra em três dimensões. Os partidos políticos brasileiros parecem sofrer das consequências esperadas pelo consenso acadêmico dedutivo: a lista aberta estimula campanhas centradas em candidatos, não em partidos (SAMUELS, 1999; CARVALHO, 2000) e gera forte competitividade entre candidatos da mesma legenda (KATZ, 1986), o que enfraquece o papel dos partidos no processo eleitoral e consequentemente empodera políticos individualmente. O comportamento eleitoral também parece ser personalizado: pesquisas de opinião (IUPERJ, 2002) revelam que 92\% dos eleitores consideraram candidatos mais importantes que partidos para decidir o voto, sendo que apenas quatro partidos (PT, PSDB, PMDB, PFL) foram citados mais que $2 \%$ nas respostas sobre em qual partido haviam os entrevistados votado nas eleições para deputado federal. Nicolau critica a noção disseminada de associação entre clientelismo/particularismo e sistemas eleitorais focados em candidatos: "não existe uma relação necessária entre a lista aberta e o desenvolvimento de atividade parlamentar exclusivamente associada a atender demandas dos eleitores." (NICOLAU, 2006, p. 705). Carvalho (2000 e 2003) aponta que há variações no comportamento dos deputados, mas que é difícil afirmar que deputados com votação concentrada em poucos municípios ("redutos") tem tendência a agir mais localizadamente (por exemplo: para levar recursos para esses municípios), enquanto aqueles com votação mais dispersa no Estado tem uma ação mais "universalista". Apesar disso, não deixa de pontuar a alta importância que parlamentares dão para a sua conexão com a vida municipal, parecendo ser esta uma tendência das relações dos deputados eleitos com suas bases eleitorais.

Luis Felipe Miguel (2009) também realiza uma sumarização da literatura brasileira sobre a relação entre o sistema de lista aberta e a accountability vertical. O primeiro argumento mais recorrente se encontra em Jairo Nicolau (2002; 2006) e Alberto Almeida (2006) e argúi que o sistema eleitoral vigente constrói empecilhos e incentivos negativos para que o cidadão identifique quem é o seu representante - isso se daria porque o número de eleitores que efetivamente elege os candidatos em que vota é baixo, o que desincentiva o acompanhamento dos mandatos legislativos, dedução que se reflete empiricamente em pesquisas que demonstram o baixo número de eleitores que lembram dos seus votos em eleições anteriores (NICOLAU, 2002). O segundo argumento é apresentado por Fabiano Santos (2003) e propõe que o problema é outro: “os deputados brasileiros não conhecem a sua verdadeira constituency eleitoral. Eles não possuem idéia aproximada de onde vieram os votos que contribuíram para sua eleição, por isso, não podem conhecer as preferências de seu eleitorado." 
(SANTOS, 2003) As duas teses, apesar de apontarem motivos diferentes, apresentam uma leitura negativa do sistema de lista aberta.

Estes argumentos pessimistas, porém, tem sofrido uma forte dose de críticas de diversos contornos. Figueiredo e Limongi (2002), por exemplo, chegam a questionar uma das teses mais difundidas da literatura: a de que o Brasil se trata de um exemplo de incentivo à campanha personalizada (e, por consequência, ao voto personalizado). Os autores chamam atenção para o poder dos partidos políticos na composição das listas partidárias, a grande importância da votação global de todos os candidatos de um partido no cálculo de cadeiras e as vastas prerrogativas de líderes partidários no Parlamento para limitar a ação individual de parlamentares e candidatos. A própria revisão de literatura feita por Luis Filipe Miguel sobre accountability vertical no Brasil é bastante crítica aos consensos; em suas palavras, ele busca "sustentar que tais argumentos baseiam-se em uma compreensão equivocada do funcionamento da accountability e da natureza do vínculo eleitoral no Brasil" (MIGUEL, 2010, p. 185) e aponta para o fato de que "em contextos diferentes [literatura acadêmica, Electoral Reform Society do Reino Unido, Citizens' Assembly on Electoral Reform na Columbia Britânica canadense], as listas abertas [...] podem surgir como a promessa de um controle maior dos representantes por seus eleitores, ou seja, de mais accountability.” (ibidem, p. 187). Sua tese mais forte é uma que pode ser encontrada em muitos outros críticos: a de que a crise de instituições representativas que os dados informam no Brasil é um fenômeno global em democracias liberais contemporâneas e não pode ser reduzida a uma falha específica de desenho legislativo. José Antonio Cheibub (2006) acredita que "es poco probable que la mala distribución de los escaños en la Cámara de Diputados sea una causa fundamental [del clientelismo]", que "la percepción de que la personalidad de los candidatos es la fuerza motora de las preferencias del electorado en las elecciones legislativas no ha sido demostrada" (CHEIBUB, 2006, p. 101) e que "el grado de fragmentación en la Cámara de Diputados se ha mantenido constante, en alrededor de ocho partidos efectivos, desde las elecciones de 1990.” (ibidem, p. 102) Já há algum tempo, entretanto, o número de partidos efetivos passou de dez na Câmara: em 2018 chegou a $16^{6}$.

Mesmo que uma literatura menos pessimista sobre o sistema proporcional de lista aberta tenha tomado uma posição maior no campo, é impossível negar a repercussão intelectual e política das primeiras teses apreensivas. O relatório-proposta do Tribunal Superior Eleitoral é profundamente informado por essas: a fórmula atual é problemática por causa da sua "baixa representatividade, pois o eleitor não sabe exatamente quem o seu voto elegeu e o candidato não tem como saber por quem

6 Ver: https://www1.folha.uol.com.br/poder/2018/10/fragmentacao-de-partidos-recorde-e-aberracao-mundial.shtml 
foi eleito. Vale dizer: um não tem de quem cobrar e o outro não tem a quem prestar contas", da fragmentação do quadro partidário, do "fato de que os primeiros adversários do candidato de um partido são os demais candidatos do mesmo partido" e porque "o debate público não é programático, mas personalizado." (TSE, 2019, p. 4).

\section{O SISTEMA DISTRITAL MISTO: "AUMENTAR A REPRESENTATIVIDADE" E "FACILITAR A GOVERNABILIDADE"}

As mais recentes alterações legislativas sobre o sistema eleitoral brasileiro precisam ser levadas em conta para uma compreensão mais abrangente do cenário de mudanças no qual o distrital misto pode se tornar parte central. A Emenda Constitucional 97/2017, aprovada em 01/11/2017, estipula dois dispositivos que trarão consequências a serem observadas já em 2020: o fim das coligações partidárias em eleições proporcionais e a cláusula de desempenho para acesso aos recursos do fundo partidário e ao tempo de propaganda gratuito no rádio e na televisão ${ }^{7}$. A literatura acadêmica é bastante afinada ao apontar o modelo de coligações como um dos elementos que geram fragmentação no sistema partidário brasileiro (KRAUSE \& KESTLER, 2017; MAINWARING, 1991; NICOLAU, 2015): os cálculos eleitorais, ao utilizarem a somatória global dos partidos em coligação, tornam possível pequenas legendas alcançarem representação com votação inferior ao quociente eleitoral, privilegiando e incentivando pequenos empreendimentos partidários. Nesse sentido, Jairo Nicolau (2015) realizou simulações (conscientemente limitadas) para avaliar os efeitos da proibição de coligações nas eleições de 2014: o número de partidos representados na Câmara caíria de 28 para 22. Outro desses elementos tipicamente culpados pela fragmentação é o regramento sobre o financiamento público de legendas: o acesso ao horário gratuito na televisão e nas rádios "estimula a proliferação de partidos, na medida em que os pequenos partidos conseguem mais tempo, proporcionalmente, do que os grandes" (MAINWARING, 1991, p. 42) e a distribuição de verbas do Fundo Partidário torna a criação de partidos um bom negócio "quando se considera que, em 2015, cada legenda recebeu minimamente em torno de R\$1.115.000,00.” (KRAUSE \& KESTLER, 2017, p. 95) A cláusula de desempenho enfrentaria esse problema: com a alteração da distribuição do fundo para 2019, 14 partidos estariam excluídos da captação de verbas com o resultado das eleições de 2014

\footnotetext{
7 Interessante ressaltar que a cláusula de desempenho, também chamada de cláusula de barreira, havia sido derrubada em 2006 pelo STF em resposta a duas ADIs movidas por partidos políticos (do PCdoB e do PSC). Válida depois da lei de 2017, ela segue sendo questionada judicialmente por organizações partidárias. O apontamento revela a importância de se observar o papel dos operadores jurídicos na formatação das eleições.
} 
(ibidem, p. 97). Parece seguro afirmar, portanto, que ambas alterações da Emenda estão preocupadas com enfrentar a hiperfragmentação do sistema partidário brasileiro.

E é nesse contexto que a reforma eleitoral volta a agenda política na forma do distrital misto. ${ }^{8}$ Essa nomenclatura, "distrital misto", pode levar a algumas confusões, visto que "distrito" refere-se apenas ao local onde será realizada a eleição, não ao método eletivo. O sistema proposto pelo TSE e conhecido no Brasil como "distrital misto" é o que a literatura estrangeira costuma denominar de sistema proporcional personalizado (SPP). Trata-se de nomenclatura mais adequada, tendo em vista de que o modelo possui um princípio representativo proporcional (distribuição conforme a força de cada partido), mas que combina os métodos de conversão de votos em mandatos (regras de decisão) utilizados pelo sistema majoritário e pelo sistema proporcional. ${ }^{9} 10$

Se não vejamos: a composição das Câmaras é de uma metade de parlamentares eleitos em distritos uninominais e a outra metade por candidatos eleitos pelo voto partidário. O eleitor, assim, tem dois votos: (i) um voto direto em um candidato no distrito; e (ii) outro voto em uma lista fechada apresentada pelo partido ${ }^{11}$. A regra (i) elege candidatos pela regra majoritária de um turno, a regra (ii) elege candidatos pela regra proporcional. Os distritos serão subdivisões dos Estados em número correspondente ao número de cadeiras a serem preenchidas pelo voto distrital; cada partido poderá lançar um candidato em cada distrito. O segundo voto continuará subscrito ao Estado e é endereçado a uma lista fechada e preordenada pelo partido político, constituindo um voto em legenda. Mas as regras não são independentes entre si, pois é o segundo voto - o voto partidário - que determina quantas cadeiras serão atribuídas a cada partido, sendo que as cadeiras são preenchidas primeiramente pelos candidatos eleitos nos distritos pelo primeiro voto e o restante é preenchido pelos candidatos da lista em sua ordem.

O modelo proposto é um profundamente inspirado pelo desenho alemão, o que não é nenhuma novidade no debate político brasileiro. ${ }^{12} \mathrm{~A}$ inspiração é reveladora. $\mathrm{O}$ sistema eleitoral alemão - como todos os outros - nasce como uma resposta e uma consequência ao contexto político e social do seu

\footnotetext{
8 Nas palavras quase literais de Rodrigo Maia: “Talvez o fim da coligação agora nos alerte da importância de mudar o sistema eleitoral." Ver: https://oglobo.globo.com/brasil/tse-propoemudanca-do-sistema-eleitoral-ja-para-2020-23730221

9 Para entender melhor a discussão, ver: Virgílio Afonso da Silva, A inexistência de um sistema eleitoral misto e suas consequências na adoção do sistema alemão no Brasil, Cadernos de Direito Constitucional e Ciência Política, vol. 23,1998, p. 238-243.

10 Essa elucidação é ainda mais importante porque o caráter proporcional do SPP/distrital misto é o que permite que o novo sistema seja aprovado por legislação ordinária, visto que o sistema proporcional hoje faz parte do texto constitucional brasileiro em seu artigo 45.

11 A proposta do TSE se abre para a possibilidade de uma lista semi-flexível, onde o eleitor poderia votar ou na legenda completa ou em um integrante da lista partidária, se antecedendo à possível resistência da classe política. Esse artigo, porém, se dedicará a uma análise da proposta de lista fechada.

12 Existe um longo histórico nacional de flerte com o supostamente bem sucedido sistema alemão. São exemplos: em 1958 o anteprojeto do então presidente do TSE, Ministro Edgar Costa; em 1960 o projeto de lei n. 38/60 do senador Milton Campos; o projeto de lei n. 1.036-63 do deputado Oscar Corrêa; o projeto de lei n. 2.152-64, do deputado Franco Montoro.
} 
país. Profundamente traumatizada pela curta e colapsada República de Weimar e em reconstrução pós-guerra, a Alemanha encarou o projeto de reconstrução institucional como um necessário processo de engenharia legislativa. A "sombra de Weimar" pairava sobre as elites germânicas: a sombra da fragmentação partidária extremada e da instabilidade política. O desafio em meio às barganhas partidárias e à pressão histórica ${ }^{13}$ era criar um modelo que coligasse a representação popular com a construção de um órgão funcional e governável.

\subsection{REPRESENTATIVIDADE POLÍTICA E ACCOUNTABILITY}

O primeiro dos auto-declarados objetivos do relatório do TSE é "aumentar a representatividade (a legitimidade democrática) do sistema político". Destrinchando o argumento geral sobre o tópico, isso ocorreria simultaneamente porque o voto partidário "assegura a representação proporcional das minorias políticas", "fortalece o caráter unitário e de representação dos partidos políticos”, “evita a 'paroquialização' das eleições (afasta-se o risco de cada parlamentar cuidar apenas dos interesses do seu distrito)" e "permite a inclusão na lista de quadros técnicos qualificados (economistas, juristas, médicos, jornalistas, líderes comunitários ou sindicais) [...] que poderiam elevar a qualidade do debate público" enquanto o voto nominal aproxima o eleitor de seu representante distrital pois este é mais facilmente identificável - a aposta chega a ir mais longe: nos distritos uninominais, "quando o representante candidatar-se à reeleição, o eleitor poderá verificar o desempenho do parlamentar ao longo do mandato e saber se deseja ou não reelegê-lo" (TSE, 2019).

A questão deve ser analisada de diversas perspectivas.

Há um forte consenso na literatura dedutiva sobre a expressiva diferença do vínculo entre eleitos por majoritárias em distritos uninominais e seus eleitores e eleitos por proporcionais: a ligação é efetivamente mais direta e muito mais geográfica (IDEA, 2006). A facilmente identificável dinâmica da eleição winner takes it all e o tamanho reduzido dos distritos gera uma espécie de proximidade pouco provável em eleições proporcionais. A questão imposta por muitos é por que incentivar essa espécie de representação geográfica seria um propósito relevante para democracias, enquanto outras vinculações podem parecer mais importantes aos eleitores - e essas podem ser expressas em sistemas puramente proporcionais (MIGUEL, 2009). A resposta costuma centrar-se no imperativo da accountability vertical: a capacidade de eleitores punirem políticos que realizaram

\footnotetext{
13 Para um histórico mais aprofundado desse processo, ver: ZITTEL, Thomas. Electoral Systems in Context: Germany. The Oxford Handbook of Electoral Systems, 2017. Disponível em $<$ researchgate.net/publication/319059066_Electoral_Systems_in_Context_Germany >. 27 p.
} 
mandatos insatisfatórios. Alguns dados sobre a performance do SPP na Alemanha são animadores nesse sentido: "a survey conducted prior to the 2009 elections found that 55 percent of [german] voters were able to recall the name of at least one candidate in their districts and that 30 percent were able to recall more than one candidate" (ZITTEL, 2017, p. 17). Outros, sobre o sistema majoritário estadunidense, nem tanto: baixos índices de renovação nas casas legislativas demonstram "a excessiva estabilidade dos representantes [...] faltando desafiantes que os obrigassem à adequada prestação de contas diante do eleitorado" (MIGUEL, 2009, p. 188).

Outra polêmica inesgotável sobre a eleição majoritária é que ela exige a estipulação de distritos. O desenho dos limites distritais é um complexo processo político e tem efeitos gigantescos nos resultados das eleições: a criatividade na engenharia pode resultar em distritos onde eleitores tem recortes étnicos, sociais, ideológicos etc. que favorecem demasiadamente alguns partidos em detrimento de outros. O problema é tão antigo e relevante nos Estados Unidos que possui jargão específico na ciência política: gerrymandering. ${ }^{14}$ A proposta do TSE acredita ser "possível definir parâmetros que diminuam os riscos de distritalização tendenciosa", chegando a citar estudo do órgão Centro de Liderança Pública que apontaria a viabilidade da definição de distritos "sem manipulação a partir de dados do IBGE". ${ }^{15}$ Além disso, estipula que a responsabilidade para a distritalização será do próprio Tribunal Superior Eleitoral, com antecedência mínima de um ano da data das eleições e fundamentada por pesquisas do IBGE. Mesmo com as medidas mínimas de segurança, o problema dos limites distritais é intrínseco à proposta do SPP.

O voto em lista fechada também produz alterações significativas na dinâmica da representação. Aponta-se como principal ponto positivo do desenho o incentivo para a construção de listas balanceadas e diversas, para que essas sejam capazes de atrair mais amplamente os eleitores. As listas fechadas favoreceriam, então, candidaturas mais sensíveis e menos viáveis nominalmente. Há um evidente lado positivo: maiores chances para minorias sociais e quadros técnicos ${ }^{16}$ de pouco apelo político. Mas há também um lado negativo com a consequente maior facilidade de eleição de políticos de pouca popularidade e envolvidos em escândalos, por exemplo. Outras críticas correntes são de que nas listas fechadas "los electores no tienen la oportunidad de determinar la identidad de las personas que los van a representar [...] y, por lo tanto, tampoco tienen la posibilidad de rechazarlo

\footnotetext{
14 o nome refere-se a governador do Massachusetts e vice-presidente dos Estados Unidos Elbridge Gerry que, em 1812, redesenhou os limites dos distritos eleitorais para favorecer os candidatos do partido republicano jeffersoniano.

15 A pesquisa é citada apenas com o direcionamento para o link de uma reportagem. Ver: https://oglobo.globo.com/brasil/reforma-politica-divisao-das-cidades-viavel-aponta-estudo$\underline{16260917}$

16 É, porém, profundamente questionável a associação produzida pelo relatório do TSE entre a eleição dessas figuras técnicas ("economistas, juristas, médicos, jornalistas, líderes comunitários ou sindicais" - ou, em outro trecho, "novas vocações") com alguma espécie de aumento da "legitimidade democrática" do sistema político.
} 
cuando consideran que no está ejerciendo su cargo de manera adecuada" (IDEA, 2006). Outro argumento reforça o ceticismo com a accountability: "a redução das alternativas [ao eleitor] submetidas compromete a realização da accountability, já que cresce a possibilidade de não haver nenhuma opção mais satisfatória" (MIGUEL, 2010, p. 188). Do ponto de vista da qualidade da representação política, parece também grave para alguns (ibidem) a redução da capacidade do eleitor de simplesmente manifestar-se adequadamente através do voto.

A lista fechada também afeta o sistema partidário empoderando os partidos políticos que, afinal de contas, definem a ordem das listas. ${ }^{17}$ Algumas das consequências possíveis desse fenômeno serão discutidas no tópico sobre governabilidade, mas por enquanto basta dizer que o sistema proposto gera preocupações com os poucos incentivos que nutre para que os representantes cultivem relações diretas com o eleitorado: "em países [...] que utilizam a lista fechada por longo tempo existe uma percepção de que os partidos se distanciaram em demasia da sociedade. O incentivo que os representantes têm em cultivar o trabalho partidário acabou os afastando do contato com os eleitores." (NICOLAU, 2015, p. 114)

O quadro que se desenha pelos mais pessimistas é uma Câmara composta por deputados de diferentes status e diferentes interesses: "uno responsable y comprometido ante el electorado de una determinada demarcación y otro, sin nexos geográficos específicos, comprometido con la dirigencia partidista" (IDEA, 2016, p. 110). Os do primeiro grupo se comportariam como "vereadores federais, intermediários entre interesses locais e o executivo" (ENZWEILLER, 2008 p. 130). Há alguma evidência que corrobora a preocupação: na Alemanha, existem "analyses that show systematic differences between district and list members with regard to committee assignments (Stratmann and Baur 2002), efforts to secure particularistic policies (Lancaster and Patterson 1990), constituency communication (Klingemann and Wessels 2001), and roll call behavior (Sieberer 2010)" (ZITTEL, 2017, p. 18). Essas diferenças em performance, porém, são controladas por dois fatores da política alemã: a força dos partidos políticos alemães, capazes de controlar o acesso às candidaturas e aos recursos de campanha e o sistema parlamentarista, que por natureza exige ação coesa de governo e oposição (ibidem). Os distritalistas, defrontados com essa tese, defendem que "a prática demonstra que [o vereador federal] já existe, uma vez que a imensa maioria dos Deputados Federais limita suas atividades ao encaminhamento dos pedidos de Prefeitos e lideranças locais (uma espécie de “despachante” de luxo), além de buscar recursos públicos e destiná-los à base eleitoral-territorial, nos

17 Vale ressaltar que no atual sistema de lista aberta brasileiro os partidos ainda detém bastante poder sobre candidaturas posto que controlam a verba pública do fundo partidário e do fundo eleitoral. A capacidade de manejar os recursos e escolher em que candidatos investir é um mecanismo externo ao sistema eleitoral stricto sensu que reforça o poder dos partidos. 
diversos ministérios de Brasília" (ENZWEILLER, 2008, p. 133). Mais uma vez o estudo de Carvalho (2003) sobre conexões eleitorais contribui para o debate: ele sugere que no caso brasileiro, embora não exista um problema de dois tipos diferentes de sistemas eleitorais, existem diferentes tipos de distribuição de votos para os deputados: alguns com votação mais concentrada, outros, com votação mais dispersa. Isso, entretanto, não produz uma divisão clara do tipo de comportamento parlamentar, resultando em combinações diversas entre votação (dispersa/concentrada) e ação legislativa (localizada/particularista x "universalista").

Outra crítica recorrente se refere a complexidade cognitiva exigida para a total compreensão do sistema. Fala-se de um sistema que exigiria dos eleitores nas eleições gerais até oito escolhas. Além disso, o número de distritos eleitorais precisaria ser diferente para as eleições da Câmara e das Assembleias Legislativas, o que resultaria em distritos justapostos - causa de ainda maior dificuldade de compreensão e estratégia até mesmo para candidatos e partidos. Nesse tópico, pesquisas demonstram que "German voters are increasingly able to distinguish between the candidate and the party vote" (ZITTEL, 2008, p. 18). Dificultar a inteligibilidade do eleitor, porém, em um país de baixa escolaridade e altas taxas de voto branco e nulo como o Brasil pode ter efeitos muito negativos para a legitimidade e a representatividade da democracia (NICOLAU, 1999).

Finalmente, é necessário apontar para o fato de que o SPP proposto pelo TSE se diferencia significativamente do modelo alemão ao excluir da regra o dispositivo das cadeiras suplementares um aumento no número total de cadeiras quando um partido elege mais candidatos nos distritos do que o número de vagas conquistadas pelo voto em lista partidária. Se hoje o sistema alemão é "widely considered more than satisfactory" (ZITTEL, 2017, p.12) em criar um sistema proporcional de distribuição de cadeiras, em boa medida esse sucesso é creditado às cadeiras compensatórias e a um sistema partidário altamente institucionalizado que evita votos quebrados (ibidem) - outra característica que o Brasil certamente não partilha.

\subsection{GOVERNABILIDADE E FRAGMENTAÇÃO PARTIDÁRIA}

O SPP ainda seria capaz de facilitar a governabilidade. O relatório aponta que "a fragmentação do quadro partidário e a falta de conteúdo programático na atuação dos partidos dificultam [...] negociações plenamente institucionais e republicanas". O sistema eleitoral aparece como uma causa desses fenômenos porque dele resulta "o fato de que os primeiros adversários do candidato de um partido são os demais candidatos do mesmo partido", o que torna o debate público mais personalizado 
do que programático, visto que "o candidato precisa convencer o eleitor de que é melhor do que o seu colega de partido". O SPP enfrenta esses problemas: ele "fortalece o caráter unitário e de representação dos partidos políticos", retira o elemento de competição intra-partidária da campanha eleitoral e “evita a 'paroquialização' das eleições (afasta-se o risco de cada parlamentar cuidar apenas dos interesses do seu distrito)" (TSE, 2019).

Há uma forte dose de argumentação dedutiva e quase intuitiva na tese. Primeiramente, é fato de que tanto na regra majoritária uninominal onde cada partido escolhe apenas um candidato e na regra de lista fechada de voto em legenda a competição intra-partidária se dá nos períodos prévios a eleição, onde tais candidaturas e suas ordens serão definidas através dos processos partidários. Durante a campanha, os candidatos possuem todos os incentivos para consolidarem uma boa imagem partidária. Supostamente, esses incentivos ajudariam a produzir um sistema político com maior enfoque em programas e ideias, em prejuízo do enfoque personalista denunciado como regra nos dias de hoje. O processo interno de cada partido para definição de nomes, porém, não é alcançado pela legislação eleitoral: esse é um problema assumido pelo próprio relatório do TSE: "não se devem ignorar as dificuldades possíveis, que incluem a atual falta de democracia interna dos partidos". (TSE, 2019, p. 5)

Trata-se de problema que não é pequeno: no SPP, os partidos políticos possuem maior força organizacional nas eleições; os candidatos devem muito mais às suas eleições aos seus partidos. Isso se dá em boa parte pelo processo de escolha de candidaturas. Tal processo pode crescer em importância à medida em que toma papel mais central nas eleições, mas há uma resistência política e acadêmica a ideia de regulamentar em demasia as políticas internas das grandes associações civis que são os partidos políticos - que deveriam gozar de autonomia e liberdade de gestão interna.

Por outro lado, a maior dependência dos candidatos a seus partidos pode enfrentar o problema da deslealdade e da fraqueza partidária. Como já dito, na experiência alemã, esse poder dos núcleos diretores dos partidos é um dos fatores que garante coesão e governabilidade e desincentiva o personalismo e o clientelismo: "this functional role of party organizational chapters provides constraints on personal vote-seeking behavior and suggests to legislators that they should represent geographic constituencies without disturbing party unity" (ZITTEL, 2017, p. 19). Outro argumento otimista em relação a coesão partidária é que a própria espécie de vínculo do voto gera incentivos diferentes: "em um modelo de lista fechada, como os eleitores votam apenas na legenda e não em nomes específicos, faz pouco sentido esperar que os deputados representem territórios do país; deles é esperado que representem o programa partidário" (NICOLAU, 2015, p. 110). 
Outro consenso acadêmico e dedutivo da literatura que aparece como intencionalidade aqui é o de que as regras majoritárias tendem a construir uma centralização do sistema partidário em números mais reduzidos de partidos efetivos. O manual IDEA de Sistemas Eleitorais chega a citar como uma vantagem do sistema majoritário o fato de que ele

\begin{abstract}
Brinda una opción claramente definida a los electores entre dos partidos $\mathrm{u}$ opciones principales. En muchos casos, las desventajas intrínsecas que enfrentan los otros partidos y minorías fragmentadas bajo el sistema de mayoría simple provocan que el sistema de partidos gravite hacia una alternancia en el poder entre un partido de "izquierda" y otro de "derecha". Los terceros partidos a menudo se debilitan y casi nunca alcanzan el apoyo popular necesario a nivel nacional para obtener un porcentaje análogo de escaños en la legislatura. (IDEA, 2017, p. 40)
\end{abstract}

O SPP, obviamente, é um sistema proporcional com regras mistas, mas é interessante ressaltar as vastas expectativas de concentração na utilização de uma regra majoritária simples: para um país com 33 partidos políticos, adotar, mesmo que parcialmente, uma regra decisória que seria capaz de fomentar um bipartidarismo "claramente definid[o]".

Se é verdade que essa adoção poderá realmente trazer resultados que vão nesse sentido, ressalta-se que o SPP é um sistema fundamentalmente proporcional. O seu sistema de duas regras, sob fundamentação proporcional, gera a possibilidade de um fenômeno bastante específico: o voto dividido - quando o eleitor vota em um partido na lista e em outro partido no distrito. Quando generalizado, ele pode resultar em um alto nível de desproporcionalidade votos - cadeiras. A Alemanha enfrentou esse problema e o respondeu com as cadeiras suplementares. Paralelamente, "in recent years, party system fragmentation is on the rise in German politics" (ZITTEL, 2017, p. 16). Mesmo que isso seja verdade, o que é lá apontado como um "all-time high" número de 4.81 partidos efetivos em 2009 (ibidem) está longe dos nossos números de 16 partidos efetivos em 2018. É um arranjo diferente o proposto pelo relatório do TSE: a exclusão das cadeiras suplementares pode agir para controlar os efeitos fragmentadores do voto quebrado, mas questiona-se se as consequências serão (i) suficientes e (ii) demasiadamente desproporcionais, visto que os eleitores brasileiros tradicionalmente votam em candidatos de diferentes partidos (NICOLAU, 1999). Como citado anteriormente, a literatura aponta para a institucionalização do sistema partidário alemão como o principal fator que mitiga os efeitos dos votos quebrados: "[it] makes behavioral incentives resulting from the list tier project to the nominal tier rather than the other way round (Cox 1997)", "renders (partisan) voters less likely to vote for independent candidates at the SMD tier or to split tickets", "renders independent candidates less likely to run at the SMD level (Moser and Scheiner 2004)", "makes parties less likely to enter into alliances or to strategically circumvent the compensation 
mechanism [...] (Bochsler 2012)" (ZITTEL, 2017, p. 13). O debate aqui acaba se concentrando em uma dilema do "ovo e da galinha": os céticos apontam para um sistema partidário institucionalizado como uma necessidade para o SPP, os otimistas fazem o exato contrário.

Outra questão central pode frustrar as expectativas de centralização: a Alemanha possui uma alta cláusula de barreira. Um partido lá só possui direito a representação no parlamento se atinge 5\% de votação em todo território nacional ${ }^{18}$. Essa alta cláusula é consensualmente tida como a principal responsável pela concentração do sistema partidário alemão. Ela fez com que pequenos partidos migrassem aos partidos maiores (KRAUSE \& KLESTER, 2017), "resulted in psychological effects preventing German voters from wasting their votes" e afetou negativamente "the electoral fate of very small parties [and] also the fate of temporarily surging parties" (ZITTEL, 2017, p. 16). Não possuímos nada similar. Nossa única cláusula de desempenho, recém aprovada e já citada, se refere ao acesso dos partidos aos fundos públicos de financiamento. Evidentemente, a falta de dispositivo do tipo mitigará - e muito - os efeitos sobre o sistema partidário.

Finalmente, o projeto de atacar a hiperfragmentação partidária brasileira não é consensual. Há quem aponte, por exemplo, que a fragmentação partidária sequer é um problema tão central para o Brasil - um ponto de vista que esse artigo considera cada vez mais mais difícil de sustentar depois de 2018 e o recorde de 16 partidos efetivos. Outros estão preocupados com a perda de representatividade que o enfraquecimento de partidos políticos pequenos pode representar: a tese é de que alterar apenas o sistema eleitoral, sem preocupar-se com "aspectos mais importantes para o aprimoramento da representação, relacionados à democratização da informação e ao fortalecimento da sociedade civil" (MIGUEL, 2010, p. 183) gera a exclusão de correntes de opinião das arenas decisórias, principalmente as mais radicais (que não necessariamente são vistas como negativas nesse prisma) e a desresponsabilização de governos de ampliar consensos sociais lidando com minorias políticas, consequentemente numa perda quali e quantitativa na expressão da vontade popular (ibidem).

\section{CONSIDERAÇÕES FINAIS}

Sistemas eleitorais não são fórmulas prontas e inequívocas prontas para manuseio e aplicação por governantes ao redor do mundo. Suas aplicações respondem à dinâmicas e contextos próprios de

\footnotetext{
18 "Para a distribuição dos mandatos das listas partidárias das unidades federadas, somente são considerados partidos aptos a obterem representação os que atingiram $5 \%$ da votação no segundo voto (de lista proporcional) ou os que, ao menos, elegeram um candidato em um distrito de uma unidade federada por meio do primeiro voto (voto distrital majoritário). Esta garantia de representação abaixo de 5\% foi ampliada, em 1956, para a exigência mínima de direito à representação, se uma legenda elege no mínimo 3 candidatos pelo voto distrital.” (KRAUSE \& KLESTER, 2017, p. 88)
} 
cada local e sua adequação é situacional, não universal. Além disso, sua construção e revisão legislativas, sua entrada e saída da agenda pública, não deve-se perder de vista, são operadas por atores políticos auto-interessados.

O contexto brasileiro é um de profunda crise política e econômica. A eleição de Jair Bolsonaro (PSL) para a Presidência da República em sua primeira campanha eleitoral para o executivo dentro de um partido nanico no qual havia se filiado pouco mais de um ano antes do pleito trouxe de volta para o centro do debate público algumas questões: o personalismo da política brasileira, a abertura aos radicalismos ideológicos, a fraqueza dos partidos políticos e sua baixíssima capilaridade social. O fim do caminho de estabilidade do semi-bipartidarismo representado pelas duas décadas de disputa PT x PSDB alertou a academia e diminuiu o otimismo daqueles que apostavam em uma crescente consolidação e institucionalização do sistema político nacional. O resultado eleitoral, é claro, é reflexo de uma outra profunda crise: a de representatividade e legitimidade pela qual passa o Estado e seus operadores em seus mais diversos órgãos, em boa parte causada pelos desdobramentos da Operação Lava Jato, que revelou gigantes escândalos de corrupção nos mais diversos níveis do governo e do mundo privado.

Nesse momento chave, a reforma eleitoral pelo sistema proporcional personalizado aparece como uma oportunidade de enfrentar essas questões. Aposta-se que os deputados distritais, por exemplo, possam gerar uma reaproximação com a população que reanime a simpatia pelo processo democrático. Junto a isso, como a proibição das coligações e a cláusula de desempenho indicam, há um caminho sendo traçado com a clara intenção de enfrentar a hiperfragmentação do sistema partidário e fortalecer os partidos políticos com melhores resultados eleitorais. Esse fim deve ser encarado com uma dose de realismo: se é verdade que boa parte da literatura sobre democracia acredita que partidos políticos institucionalizados, fortes e com simpatia popular são agentes mediadores fundamentais para o melhor funcionamento do sistema, não há de se esquecer que justamente nossos maiores partidos estão sendo postos sistematicamente em xeque pelo escrutínio popular e pelo judiciário. Faz sentido para esses atores políticos se movimentar de modo a fortalecer seus oligopólios eleitorais forçando a migração de pequenos partidos ao sufocar suas chances eleitorais; faz sentido também para as elites partidárias, muitas afogadas em escândalos, aumentarem seu poder e influência por reformas legais e suas chances de eleição através, por exemplo, das listas fechadas.

Mesmo assim, com 33 partidos, 16 efetivos na Câmara dos Deputados, é impossível negar que o Brasil possui números anormais globalmente que diminuem a eficiência e aumentam os custos 
e as negociatas ilegais na operação política. Se o ceticismo pode ajudar a entender as motivações dos agentes, ele ainda deixa aberta a pergunta: as consequências práticas dessa mudança tem mais potencial positivo ou negativo para a democracia brasileira?

A resposta para essa pergunta tem um caráter evidentemente normativo e depende fundamentalmente de concepções de democracia. Esse artigo buscou apenas contribuir para a discussão realizando uma breve revisão e esquematização do debate a nível local e sua situação no país-modelo da reforma proposta.

\section{REFERÊNCIAS}

ALMEIDA, Alberto. Amnésia eleitoral: em quem você votou para deputado em 2002? E em 1998? In: SOARES, G. A. D. \& RENNÓ, L. R. (orgs.). Reforma política: lições da história recente. Rio de Janeiro: Fundação Getúlio Vargas. 2006.

AMES, Barry. Electoral Strategy under Open-List Proportional Representation. American Journal of Political Science, vol. 39, no 2, 1995. p 406 - 433.

CARVALHO, Nelson Rojas de. Peço a Palavra: Primeiro Nós. InsightInteligência, vol. 9. 2000. p. 89 - 96.

E no Início Eram as Bases: Geografia Política do Voto e Comportamento Legislativo no Brasil. Rio de Janeiro, Editora Revan. 2003.

CHEIBUB, José Antonio. Brasil: representación proporcional centrada en los candidatos en un sistema presidencial. In: Instituto Internacional para la Democracia y la Asistencia Electoral (org.). Diseño de sistemas electorales. Tlalpan, 2006. p. 99 - 103

ENZWEILLER, José Romano. Dimensões do sistema eleitoral: o distrital misto no Brasil. Revista Direitos Fundamentais \& Justiça, nº 3, Porto Alegre, Abr./Jun. 2008. p. 113 - 138

FIGUEIREDO, Argelina \& LIMONGI, Fernando. Incentivos eleitorais, partidos e política orçamentária. Revista DADOS, Rio de Janeiro, v. 45, n² 2. Disponível em < http://www.scielo.br/ pdf/dados/v45n2/10790.pdf >. 2002. p. $303-44$.

INSTITUTO INTERNACIONAL PARA LA DEMOCRACIA Y LA ASISTENCIA ELECTRORAL (org.). Diseño de sistemas electorales: el nuevo manual de IDEA Internacional. Tlalpan, 2006. 224 p.

KATZ, Richard S. Intraparty Preference Voting. In B. Grofman e A. Lijphart (eds.), Electoral Laws and Their Political Consequences. New York, Agathon Press. 1986.

KRAUSE, Silvana \& KESTLER, Thomas. Sistemas Eleitorais: um diálogo comparado Brasil e Alemanha. Cadernos Adenauer XVIII, nº 4, Rio de Janeiro, 2017. p. 81 - 101

MAINWARING, Scott. Políticos, partidos e sistemas eleitorais: o Brasil numa perspectiva comparada. Revista Estudos, nº 29, São Paulo, Mar. 1991. p. 34 - 58 
MIGUEL, Luis Felipe. Accountability em listas abertas. Revista de Sociologia e Política v. 18, $\mathrm{n}^{\circ}$ 37, Curitiba, Out. 2010. p. 183 - 200

NICOLAU, Jairo. De como pensando-se que vai para a Alemanha, chega-se à Bolívia. Boletim de Análise de Conjuntura Política. Belo Horizonte, n. 6, abril/1999.

. Como controlar o representante? Considerações sobre as eleições para a Câmara dos Deputados no Brasil. Dados, Rio de Janeiro, v. 45, n. 2, 2002. p. 219 - 236.

Como aperfeiçoar a representação proporcional no Brasil. Revista Cadernos de Estudos Sociais e Políticos, v.4, nº 7, Rio de Janeiro, Jan./Jun. 2015. p. 101 - 121

O Sistema Eleitoral de Lista Aberta no Brasil. Revista DADOS - Revista de Ciências Sociais, v.49, no 4, Rio de Janeiro, 2006. p. 689 - 720

SAMUELS, David. Incentives to Cultivate a Party Vote in a Candidate-Centric Electoral System. Comparative Political Studies, vol. 32, no 4, 1999.

SANTOS, F. O poder Legislativo no presidencialismo de coalizão. Belo Horizonte: UFMG. 2003.

TRIBUNAL SUPERIOR ELEITORAL. Contribuição do para o debate acerca da reforma do sistema eleitoral brasileiro: o sistema distrital misto como alternativa a ser testada. 2019. Disponível em < http://www.tse.jus.br/imprensa/noticias-tse/arquivos/reforma-do-sistema-eleitoral >. 15 p.

ZITTEL, Thomas. Electoral Systems in Context: Germany. The Oxford Handbook of Electoral Systems, $2017 . \quad$ Disponível em researchgate.net/publication/319059066_Electoral_Systems_in_Context_Germany >. 27 p. 